\title{
Time-frequency analysis of heart rate variability during immediate recovery from low and high intensity exercise
}

\author{
Kaisu Martinmäki · Heikki Rusko
}

Published online: 15 March 2008

(C) Springer-Verlag 2008

Erratum to: Eur J Appl Physiol (2008) 102:353-360

DOI 10.1007/s00421-007-0594-5

Unfortunately, the statistical differences for normalized low $\left(\mathrm{LFP}_{\mathrm{nu}}\right)$ and high frequency power $\left(\mathrm{HFP}_{\mathrm{nu}}\right)$ during a low intensity exercise (LI) session in Fig. 1 were reported incorrectly. Figure 1, as corrected, is shown below. Neither $\mathrm{LFP}_{\mathrm{nu}}$ nor $\mathrm{HFP}_{\mathrm{nu}}$ differed statistically between the stationary phases of the LI session, as correctly stated in the text.

The online version of the original article can be found under doi: 10.1007/s00421-007-0594-5.

K. Martinmäki · H. Rusko

KIHU, Research Institute for Olympic Sports,

Jyväskylä, Finland

K. Martinmäki · H. Rusko

Department of Biology of Physical Activity,

University of Jyväskylä, P.O. Box 35 (LL),

40014 Jyväskylä, Finland

K. Martinmäki ( $\square)$

Rautpohjankatu 8, 40700 Jyväskylä, Finland

e-mail: kaisu.martinmaki@ sport.jyu.fi 

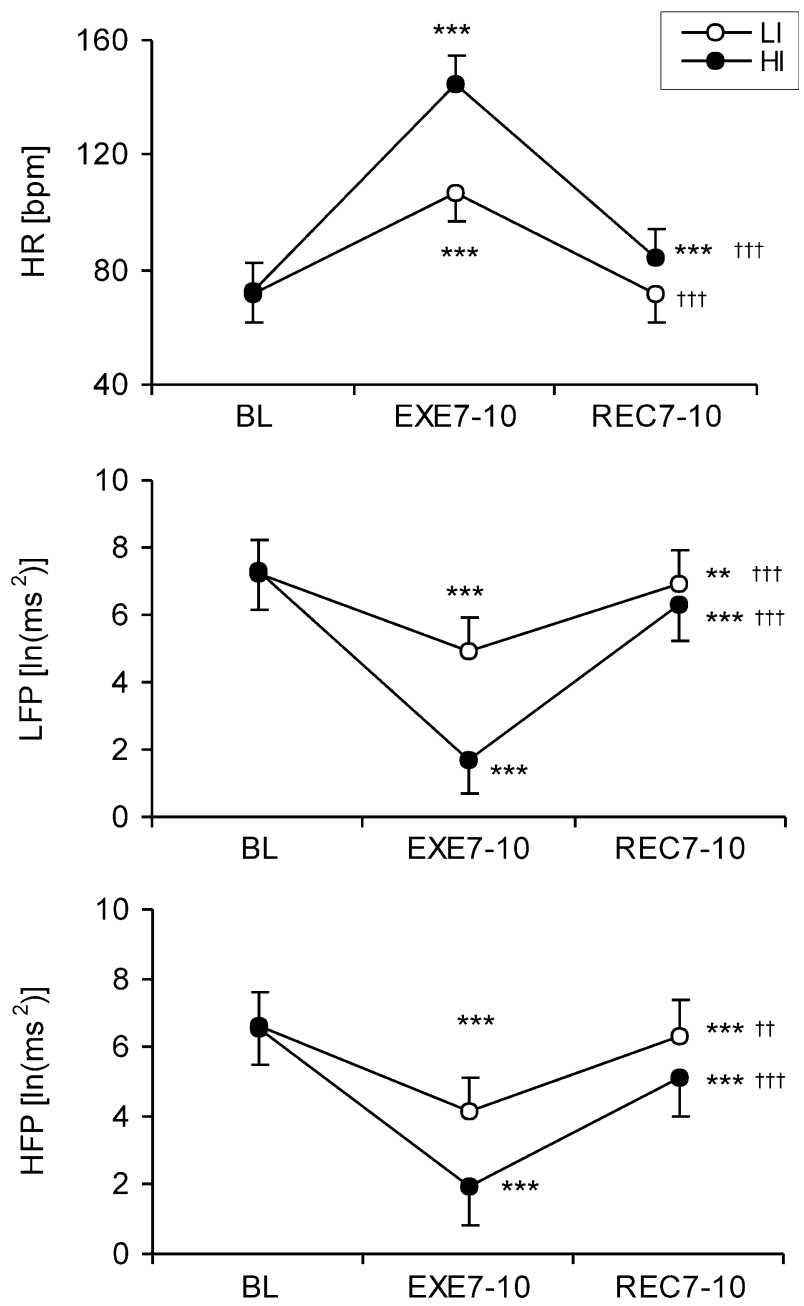
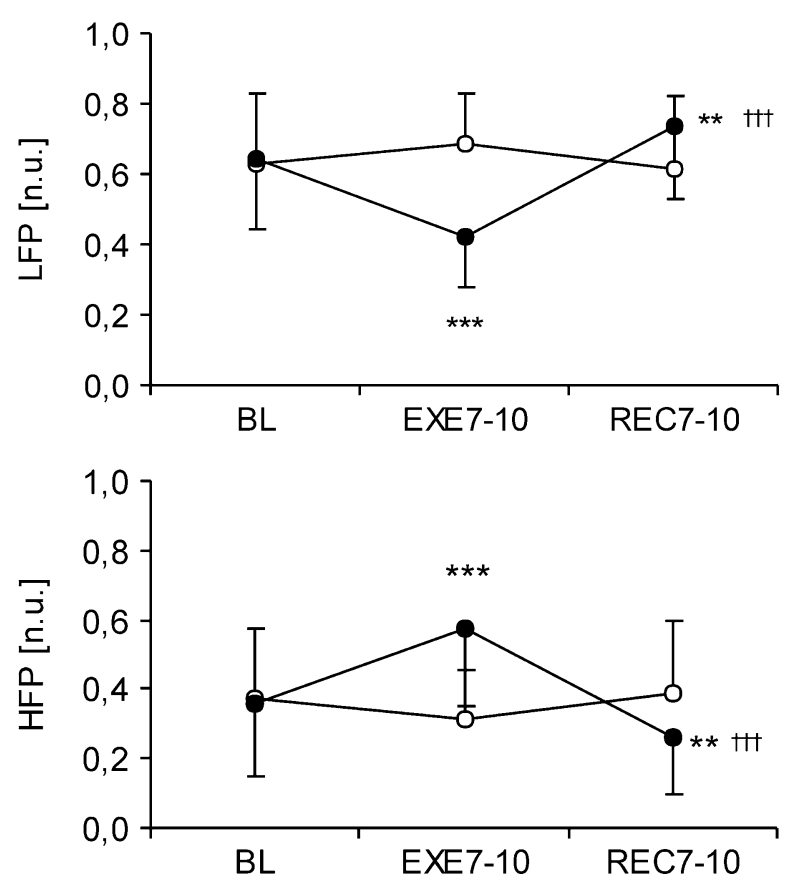

Fig. 1 Heart rate and the FFT derived heart rate variability indices during the stationary phases of the experiment, i.e. the sitting baseline $(B L)$, during the exercise $\left(\mathrm{EXE}_{7-10}\right)$ and recovery $\left(\mathrm{REC}_{7-10}\right)$ minutes seven to ten. $L I$ low intensity exercise, $H I$ high intensity exercise, $H R$ heart rate, $L F P$ low frequency power, $H F P$ high frequency power. Statistically significant difference compared to $\mathrm{BL}$ at $* * P<0.01$ and $* * * P<0.001$, compared to $\mathrm{EXE}_{7-10} \dagger \dagger P<0.01$ and $\dagger \dagger \dagger P<0.001$ 